\title{
PROTESTAS. UNA CONTRIBUCIÓN DEL INSTITUTO DE INVESTIGACIONES SOCIALES (IIS-UCR) A LA INVESTIGACIÓN DE LOS MOVIMIENTOS SOCIOPOLÍTICOS EN COSTA RICA
}

Alejandro Alvarado Alcázar

PROTESTAS ${ }^{1}$, base de datos de acciones colectivas, es una herramienta en línea disponible para consulta pública, centrada en el seguimiento de la protesta social en Costa Rica. ${ }^{2}$ Actualmente, cuenta con registros actualizados desde diciembre del 2014, a los cuales se agregan nuevos datos mes a mes. Para lograr esto se mantiene un monitoreo constante de los reportes de prensa de tres medios de comunicación escrita, ${ }^{3}$ en sus versiones digitales, con el fin de identificar los tipos de acción colectiva, actores colectivos y demandas. Adicionalmente, se clasifican otras categorías como las entidades, tanto públicas como privadas, hacia las que son dirigidos los reclamos y las formas de represión de la protesta social. También se establece, cuando es posible, el lugar dónde ocurre la acción colectiva, para identificar la ubicación geográfica (niveles provincial y cantonal) y los posibles procesos de territorialización de la protesta social. De esta manera, para cada acción colectiva se construye una tabla de registro en donde se ingresa toda la información relacionada con la misma, reportada en las fuentes mencionadas.

\section{¿Por qué?}

Para América Latina el año 2000 marcó un punto de giro en términos de la acción sociopolítica. Dicho momento ha sido considerado por la literatura académica como un nuevo ciclo de movilización contra las consecuencias sociales, económicas y políticas del neoliberalismo en toda la región (Seoane y Taddei, 2000; Svampa, 2009; Parra, 2011). ${ }^{4}$ La continuidad de viejos conflictos sumada a la reemergencia de "nuevos" actores sociopolíticos -indígenas, campesinos, mujeres, etc.- dibujó el complejo mapa de la protesta social contemporánea en el escenario latinoamericano.

En el caso costarricense, la década pasada inició con las luchas sociales contra el llamado Combo ICE (Instituto Costarricense de Electricidad), en las cuales un conjunto heterogéneo de actores sociopolíticos derrotó los intentos de privatización de las telecomunicaciones que hasta ese momento estaban en manos estatales. Tal como sucedió en otros países de la región, la llegada de políticas neoliberales se 
tradujo en choques entre organizaciones sociopolíticas y el Estado, lo cual configuró un panorama de resistencias callejeras ante dichas políticas. Casi un lustro más tarde, y durante varios años, nuevamente una diversidad de actores se movilizó contra el Tratado de Libre Comercio con los Estados Unidos (CAFTA-DR, por sus siglas en inglés) desembocando en un referéndum para decidir el futuro de dicho tratado.

De la mano de este ciclo de luchas sociales, sectores académicos y no-académicos y organizaciones sociopolíticas de distinto tipo han producido conocimiento alrededor de las experiencias de resistencia contra el neoliberalismo en América Latina y en relación con el resurgimiento de toda una serie de nudos de conflictualidad social de los grupos subalternos.

De esta manera nació el interés en el IIS-UCR, en conjunto primero con el Estado de la Nación y posteriormente con el Consejo Latinoamericano de Ciencias Sociales, ${ }^{5}$ de mantener un seguimiento sistemático de las acciones colectivas en Costa Rica, con el fin de contribuir con la producción de conocimiento en relación con los movimientos sociopolíticos en el país.

\section{¿Cómo?}

Las tres categorías centrales de registro son:

1. TIPO DE ACTOR COLECTIVO: son todos aquellos grupos, organizaciones o movimientos que se movilizan para demandar una respuesta frente a las necesidades de distinta índole. Si bien la base de datos registra una variedad de actores colectivos, el énfasis está colocado en todos aquellos que hacen uso de la acción colectiva de protesta como mecanismo predominante de expresión de sus demandas. De esta manera, entre los principales tipos de actor colectivo se encuentran los denominados "tradicionales" como las y los trabajadores (y los sindicatos), las y los campesinos y las y los estudiantes y los llamados "nuevos" movimientos sociales como las mujeres, la población indígena, el sector ambientalista (en sus distintas expresiones como ecologistas, conservacionistas, etc.) y las organizaciones LGBTI. También se incluye un conjunto de otros grupos $u$ organizaciones como es el caso de los vecinos ${ }^{5} \mathrm{y}$ las cámaras empresariales.

2. TIPO DE ACCIÓN COLECTIVA: la acción colectiva encierra un conjunto plural de expresiones de protesta social que incluyen desde las formas convencionales hasta la no-convencionales. Por formas convencionales de acción colectiva se entiende todas aquellas manifestaciones que transcurren centralmente mediante los mecanismos de la institucionalidad formal. Entre ellas estarían la declaración pública, las reuniones con autoridades de gobierno, las denuncias ante entidades nacionales o internacionales. 
Por su parte, las no-convencionales son aquellas donde la "calle" como espacio potencial de construcción autonómica cobra centralidad. Se trata de la "toma" material e inmaterial-simbólica de los espacios públicos, resignificados como terrenos de confrontación. Entre estas se puede mencionar el paro, la huelga, la marcha, el bloqueo y la toma de propiedades. Asimismo, en ciertos casos el carácter convencional o no-convencional de una determinada acción colectiva no está dado por su forma, sino por el sentido de lo político que los sujetos le otorgan.

3. TIPO DE DEMANDA: las demandas colectivas conforman un escenario de enorme complejidad, debido a la amplia variedad de reclamos por donde se movilizan los actores colectivos. Estos incluyen desde los característicamente gremiales como es el caso de la defensa de las condiciones laborales, en un sentido amplio, de los trabajadores, tanto en el sector público como en el privado y en otros como el caso de quienes desempeñan labores informales, hasta las demandas generales como la defensa de la salud o de la educación. También se consideran las protestas sociales generadas por la defensa de los servicios públicos esenciales. Otra de las temáticas fundamentales es aquella relacionada con la gestión de la función pública y el gobierno. Asimismo, están contempladas las demandas alrededor de los llamados procesos de acumulación por desposesión, entre ellas de las nuevas formas de la lucha socioambiental y la defensa de la tierra/territorio.

De dicho registro, se construyen las cronologías de la protesta social, publicadas cada mes, donde se presentan de manera resumida datos cuantitativos y cualitativos sobre el comportamiento de las acciones colectivas sociopolíticas en Costa Rica. Las cronologías constituyen un insumo en miras de mantener un monitoreo de los procesos de movilización sociopolítica en el país, lo cual genera información de interés tanto para fines académicos como extracadémicos.

Junto con esto, se mantiene una base de datos de noticias sobre acciones colectivas, que están disponibles para descarga, lo cual les permite a los usuarios potenciales tener acceso a la fuente primaria de información. Entre otros usos, esta base de datos representa un insumo para quienes se interesen en desarrollar análisis de contenido, y sobre cómo los medios de comunicación representan la protesta social y a los actores colectivos en el país.

Otros de los insumos puestos a disposición de los usuarios en el sitio son los generadores de gráficos y mapas, mediante los cuales se puede procesar la información disponible en la base de datos, en otros formatos gráficos.

También se ha generado un sistema de etiquetas (o palabras clave) para identificar cada registro de protesta social de acuerdo con descriptores específicos y para posibilitar la búsqueda cruzada de información. De esta forma, los usuarios 
pueden generar información alrededor de temáticas específicas, cruzando información de distinto tipo. Por ejemplo, quien está interesado en identificar todos los registros relacionados con personas migrantes tiene la posibilidad de seleccionar la etiqueta específica y esta desplegará la información agregada sobre el tema, esté o no relacionada con sus derechos como migrantes o con otros temas como las condiciones laborales de estas personas en las plantaciones de piña en la Zona Norte de Costa Rica o en la construcción de megadesarrollos comerciales.

\section{¿Para qué?}

Las bases de datos constituyen una herramienta de suma utilidad para el almacenamiento y procesamiento de información de distinta naturaleza. En el caso de las Ciencias Sociales, las bases de datos son comúnmente utilizadas con fines académicos inmediatos, en especial por investigadores que hacen uso de estas para reconstruir parte de sus objetos de estudio, sobre todo en disciplinas como la historia.

No obstante, lo usual es que dichas bases de datos sean de uso privado, de acceso restringido o de paga, lo cual, en muchos casos, limita la utilidad de la herramienta. PROTESTAS se ha planteado desde su diseño inicial como una base de datos de acceso público, que permite facilitar el uso para fines académicos y extraacadémicos de personas interesadas tanto dentro como fuera de Costa Rica.

Mediante dicha herramienta se persigue, entre otras cuestiones, facilitar el seguimiento sistemático de la protesta social en Costa Rica, facilitar el monitoreo de las movilizaciones sociales mediante un registro mensual, mantener a disposición de público general y especializado datos actualizados sobre el comportamiento de la protesta social en el país. Entre otros usos posibles de la información compilada se puede señalar el mapeo de las movilizaciones sociales en el país, mediante una serie de categorías que permiten contar con un procesamiento de la información registrada en medios de comunicación, mantener (o recuperar) la memoria histórica de las luchas sociales contemporáneas, generar análisis de contenido de los medios de comunicación, entre otros. Además, dicha herramienta, consideramos, constituye un insumo importante tanto para las disciplinas de las ciencias sociales como para las mismas organizaciones involucradas en los procesos de movilización social y para el público en general.

Finalmente, mediante PROTESTAS buscamos contribuir en la recuperación de la categoría del conflicto social para entender las complejas transformaciones en la estructura social costarricense. Dicha categoría resultó sistemáticamente abandonada por el pensamiento crítico como consecuencia de la generalización de un pensamiento hegemónico centrado en gestionar el modelo económico dominante (Seoane y Taddei, 2003: 61). 
De esta manera, el conflicto como manifestación de las contradicciones propias de todo modelo económico, "retornó" de la mano de un conjunto plural de acciones colectivas y actores colectivos, los cuales visibilizaron en las calles los múltiples malestares sociales ocasionados por los cambios en curso.

\section{Notas}

1 Puede accesar a la página del proyecto en el siguiente enlace: http://www.protestas.iis.ucr. ac.cr/

2 Para efectos de este registro, la acción colectiva se entiende como toda forma de protesta social mediante la cual un determinado actor colectivo (o un grupo de ellos) expresa de manera organizada o no-organizada una demanda relacionada con temas de distinta naturaleza, sean estos político-económicos o culturales.

3 La Nación, La Extra y crhoy.com. La decisión de tomar estos tres medios de comunicación como fuentes de registro obedece a una decisión metodológica relacionada con la periodicidad y la constancia de las publicaciones. Desde luego, dichas fuentes tienen una orientación económica y político-ideológica que en muchos casos influye en la definición de lo que se considera un "hecho noticioso", esto es, lo que se reporta y lo que no se reporta y cómo se reporta. A lo largo de la investigación se han considerados otras fuentes como el Semanario Universidad de la Universidad de Costa Rica o el medio digital informatico.com.

Para autoras como Maristella Svampa, este nuevo ciclo tiene como punto de partida el levantamiento zapatista de enero de 1994 y se dinamiza en el 2000 con la llamada Guerra de Agua en Cochabamba, Bolivia (2009: 4).

Desde inicios de la década del 2000, el Consejo Latinoamericano de Ciencias Sociales, mediante la constitución de OSAL-Observatorio Social de América Latina, inicia un trabajo de seguimiento y análisis sistemática del nuevo ciclo de movilización social en la región latinoamericana. Como parte de este esfuerzo regional, el IIS-UCR se incorporó con un comité de seguimiento y análisis de la protesta social en el año 2008.

Por grupos de vecinas y vecinos se entienden todos aquellos cuyas demandas se relacionan con necesidades inmediatas de su comunidad (o barrio) como es el caso del estado de las calles o el (des)abastecimiento de agua.

\section{Bibliografía}

Parra, Marcela. "Características actuales de la movilización social en América Latina". OSAL, (2011): 43-64.

Seoane, José y Taddei, Emilio. "La conflictividad social en América Latina". OSAL, (2000): 61-65.

Svampa, Maristella. "Protesta, movimientos sociales y dimensiones de la acción colectiva en América Latina". Ponencia presentada en las "Jornadas de Homenaje a Charles Tilly". Universidad Complutense de Madrid-Fundación Carolina, 2009. < http://maristellasvampa.net/archivos/ensayo57.pdf>. 
Alejandro Alvarado Alcázar. Costarricense. Licenciado en Sociología de la Universidad de Costa Rica. Egresado de la Maestría Centroamericana en Sociología de la Universidad de Costa Rica. Es investigador en el Instituto de Investigaciones Sociales de la misma universidad, donde coordina el proyecto de Seguimiento de las Acciones Colectivas en Costa Rica.

Contacto: al.alvacazar@gmail.com 